\title{
Multiple models in social transmission of food selection by Norway rats, Rattus norvegicus
}

\author{
LIEN-SIANG CHOU* \& PETER J. RICHERSON \\ Graduate Group in Ecology, University of California, Davis, CA 95616, U.S.A. \\ (Received 15 August 1990; initial acceptance 25 September 1990. \\ final acceptance 20 February 1992; MS. number: 3630)
}

\begin{abstract}
To investigate how an observer rat integrates multiple diet information from several demonstrator rats, an observer rat was allowed to interact with a group of four demonstrators simultaneously for $30 \mathrm{~min}$, and was then offered a two-choice preference test. Each demonstrator group member had previous experience with one of two different flavoured diets. Based on different combinations of dietary experience of demonstrators, five types of demonstrator groups were formed. The relationship between the dietary preference of an observer and the ratio of the different demonstrator types in the group was investigated with Sprague-Dawley rats (females only) and Long-Evans rats (with both sexes and two age classes) in two experiments. The preference response differed significantly between observers of five demonstrator groups, and the difference increased in proportion to the ratio of the different demonstrator types. The results suggest that direct bias could be involved in the social transmission of food selection by SpragueDawley rats, but no bias is involved in the Long-Evans. The strength of social transmission did not show sex and age variation. Nevertheless, the baseline innate preference seemed to be lower for male than female rats.
\end{abstract}

In the last five decades there has emerged a body of evidence of social learning in various animals although it has been a controversial issue for about 100 years (Zentall \& Galef 1988). Most of the studies placed emphasis on either the diffusion of one invented behaviour pattern in a group of animals (Kawai 1965; Lefebvre 1986), or the details of the transmitting mechanisms (Galef 1977, 1985, 1988). Studies of transmitting mechanisms are usually accomplished in rigorously controlled laboratory settings. Typically, the experimenter manipulates an observer to interact with one demonstrator who has acquired a certain behavioural trait, and then tests the observer's learned response.

To date, little attention has been given to multiple sources of information in social transmission. Galef's (1983) multiple messages served as a limited example because the observer was tested on only one of four socially transmitted olfactory cues against another novel one in his two-choice preference test design. The other three olfactory cues from three demonstrators were irrelevant to the preference test and served only as a disturbance to the learning process of observers. Posadas-

*Present address: Department of Zoology, National Taiwan University, Taipei, Taiwan, Republic of China.
Andrews \& Roper's study (1983) included a type of multiple-information transmission. They manipulated the observers by exposing them to two different olfactory cues, one from the environment (a nearby cotton swab soaked with a flavoured solution) and the other from a demonstrator (who ate another flavoured diet). However, in their procedure, only one diet message was carried by the demonstrator. So the social transmission was still of a single piece of information.

A real rat colony often exists in a heterogeneous environment. There is likely to be more than one food resource and many olfactory cues. A naive rat is normally exposed to multiple demonstrators with variable food information either at the same time or in series. Galef \& Wigmore (1983) discussed the hypothesis that the communal burrow, where rats acquire dietary information from experienced individuals, acts as an 'information centre' in a rat society. Thus, how an animal integrates information from multiple demonstrators is an interesting question. Recently, Galef (1990) conducted a series of four experiments to test the responses of observer rats to complex, diet-related signals given by demonstrator rats. Three of these experiments, however, focused on a single dietary message. How 
rats dealt with simultaneous multiple information from demonstrators was tested in Galef's experiment 3 with similar protocol to that in Chou (1989), but with only one strain, only males, and different flavoured diets. So there is still much room left for research and discussion.

Theoretical models for social transmission with multiple demonstrators have been developed by evolutionists (Pulliam \& Dunford 1980; CavalliSforza \& Feldman 1981; Boyd \& Richerson 1985). Once an individual is exposed to a potential imitator, its effectiveness as a social transmitter may depend on some bias on the part of the observer. If no bias is involved, there should be a simple linear relationship between the input (e.g. mere time of exposure to a given social signal) and the observer's response. Bias is defined in terms of departures from such a simple linear transmission. Boyd \& Richerson (1985) described three types of bias: direct; frequency-dependent; and indirect. Indirect bias occurs when some attribute of a demonstrator, such as size, condition, or dominance status, is used as a cue for the acquisition of other target behaviour, such as dietary preference. Considerable evidence, reviewed by Galef (1988), suggests that rats have not yet shown any sign of using such attributes to weight the importance of demonstrators. For example, sick or anaesthetized demonstrators can be as effective as healthy ones (Galef \& Stein 1985), and mothers are not especially good models (Chou 1989). Thus, only direct and frequency-dependent biases are plausibly important in the social transmission of dietary preference in rats. Direct bias occurs when rats are more greatly affected by demonstrators that display a preferred diet, i.e. whose taste or smell is attractive. For example, even if only a single demonstrator signals the use of a given diet in a large set of demonstrators, direct bias might result in a substantially greater response than that given to a non-preferred diet, the odour of which is carried by a large number of demonstrators. Frequencydependent bias occurs when a naive rat uses the number of (or the ratio of) demonstrators who have a certain dietary experience as a guide to the acceptability of transmitted information. In an extreme case, an observer might eat only the food type used by the greatest number of demonstrators, even when a significant minority ate the other kind of diet (a sort of majority vote effect).

Our aims in this experiment were to investigate how rats synthesize food information from mul- tiple demonstrators and to evaluate the general applicability of the social transmission model developed from human cultural transmission to social transmission in animal societies. To accomplish this, one observer was allowed to interact with four demonstrators simultaneously. Each demonstrator carried information about one of two diets, either cocoa or cinnamon flavoured. Based on the ratios of the number of each type of demonstrator rat in each demonstrator group, five different combinations of demonstrator groups were established $(0: 4,1: 3,2: 2,3: 1$ and 4:0). After exposure to a demonstrator group, the observer was given a two-choice preference test with these flavoured diets to investigate the relationship between the observer's dietary preference and the ratio of the different types of demonstrators presented to it.

Experiment 1 investigated social transmission between adult Sprague-Dawley females. Experiment 2 investigated the variation in social transmission among different strains, sexes and age classes of Long-Evans rats.

\section{HYPOTHESES}

We modified three models of Boyd \& Richerson $(1985$, pp. $85,138,209)$ to fit the two-diet case presented here. Let $X$ be the proportion of one demonstrator type to which an observer rat is exposed. Let $Y$ be the proportion of diet eaten by (dietary preference of) the observer after social and individual learning. Then, the $Y$ of this generation will be an indicator for the $X$ of the next generation in the following social transmission when the original observer becomes a demonstrator. $I$ is the innate preference for the focal diet, which is assumed to be genetically determined and which guides individual learning. The parameter $a(0 \leqslant a \leqslant 1)$ stands for the relative importance of social transmission relative to individual learning of dietary preference. Each hypothesis is expressed by the following models.

Hypothesis 1: if no direct bias is involved in social transmission, we expect

$$
Y=a X+(1-a) I
$$

This model predicts that the relationship between the ratio of demonstrators and the observer's response is a simple linear regression line (Fig. la).

Adding factors to account for direct bias $(B)$ or for frequency-dependent bias $(D)$ to the above model produces the following two hypotheses. 

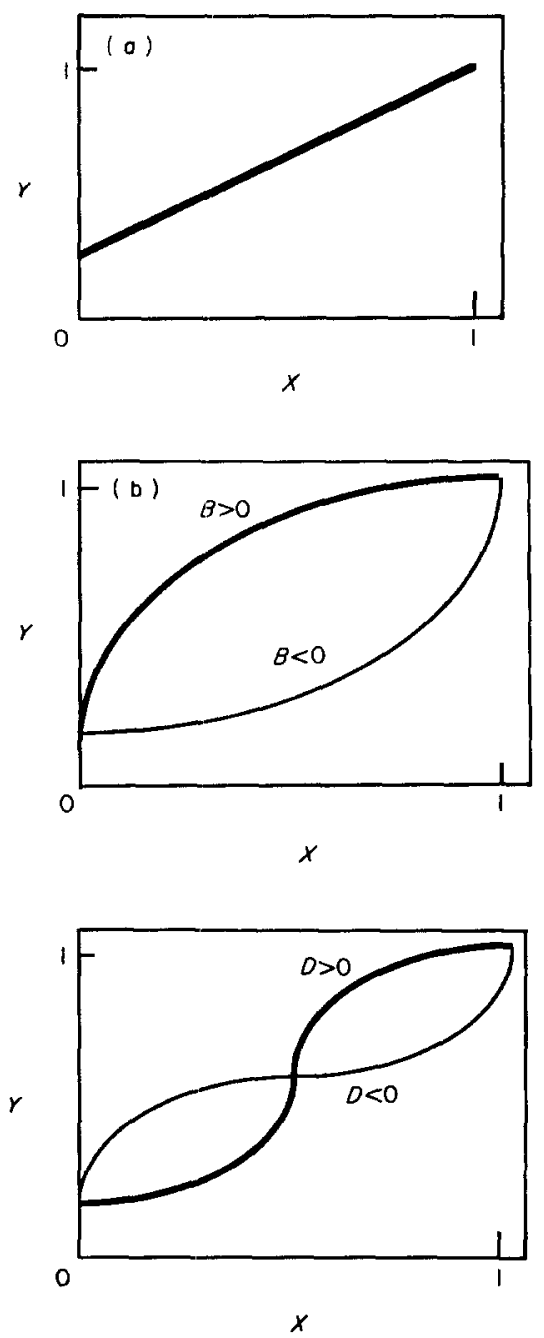

Figure 1. Theoretical relationships between the observer's preference response $(Y)$ and the demonstrator ratio $(X)$. (a) Unbiased social transmission; (b) direct biased social transmission; (c) frequency-dependent biased social transmission. $B=$ direct bias, $D=$ frequency-dependent bias.

Hypothesis 2: if a direct bias is involved in social transmission, we expect

$$
Y=a[X+B X(1-X)]+(1-a) I
$$

or,

$$
Y=(-a B) X^{2}+(a+a B) X+(1-a) I
$$

where $X$ stands for the mean value of the demonstrator's dietary preference, and $X(1-X)$ stands for the variance. This model predicts a quadratic linear regression relationship between the ratio of demonstrators and the observer's response (Fig. lb). The curve is convex when $B$ is positive (when the focal diet is preferred), and concave when $B$ is negative (when the focal diet is not preferred).

Hypothesis 3: if a frequency-dependent bias is involved in social transmission, we expect

$$
Y=a[X+D X(1-X)(2 X-1)]+(1-a) I
$$

or,

$$
Y=(-2 a D) X^{3}+(3 a D) X^{2}+(a-a D) X+(1-a) I
$$

Unlike the formula in hypothesis 2 , this equation contains a new term $(2 X-1)$. This term indicates the switching point for the sign of the functional relationship of the frequency-dependent bias to preference. No frequency-dependent bias is involved at a neutral point when $X=0 \cdot 5$, and this bias will have an additive effect when $X>0.5$, and a deducting effect when $X<0 \cdot 5$. This model predicts a cubic relationship between the ratio of demonstrators and the observer's response (Fig. Ic). When $D$ is positive (attitude towards more common model trait), the bias is towards the more common variant, a phenomenon also called conformist social transmission (Boyd \& Richerson 1985). Thus, the $Y$-value increases more slowly than in the linear regression for smaller values of $X$ (when demonstrators of the focal diet are rare) but it increases faster than in the linear regression when values of $X$ become larger (when demonstrators of the focal diet are common), as in a logistic curve. When $D$ is negative, the bias is toward the less common variant and the curve bends in the opposite way.

Hypotheses 2 and 3 are not necessarily exclusive. The combination of direct bias and frequencydependent bias makes the curve more complicated, mainly by changing the switching point of the sigmoid curve to larger or smaller than 0.5 . However, for the outcome of a quadratic curve, direct bias is the most likely mechanism, or at most with some non-significant frequency-dependent bias effect.

\section{EXPERIMENT 1: SPRAGUE-DAWLEY RATS}

\section{Methods}

Subjects

Twenty adult female Sprague-Dawley rats (70 days old) from Simonsen Laboratories, California, were assigned as demonstrators and five types of 


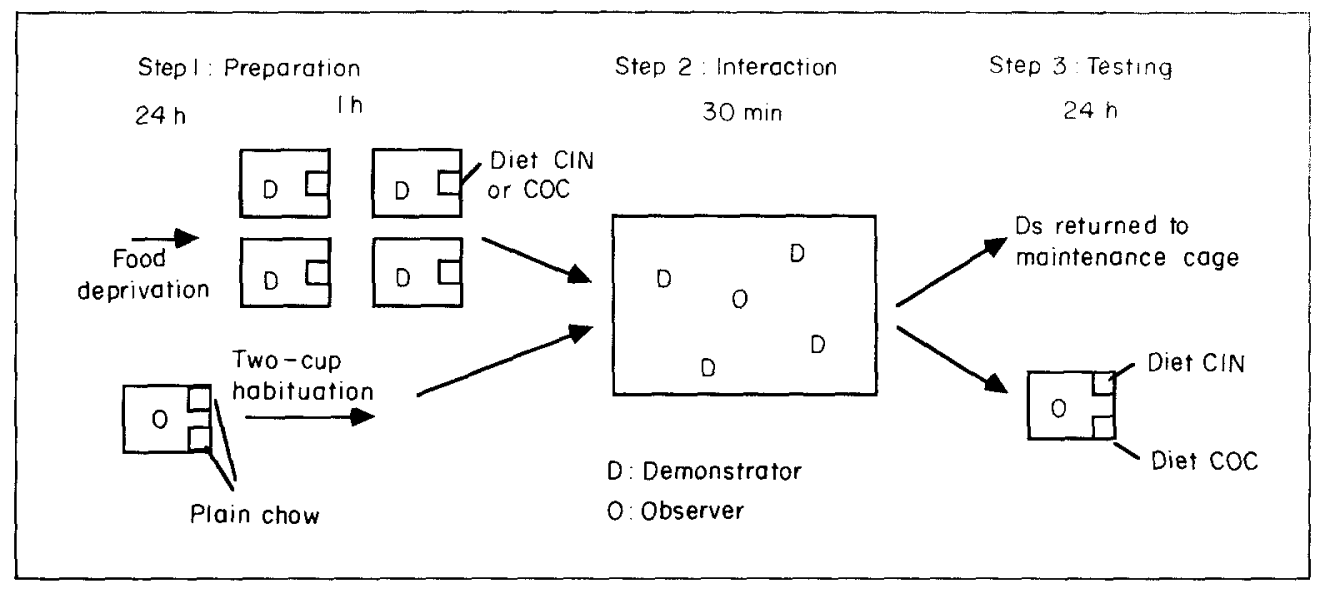

Figure 2. The paradigm for the experimental procedure.

four-member demonstrator groups were established by haphazardly selecting subjects for learning trials. Another 40 female rats served as observers and were exposed to five demonstrator groups (eight observers for each group). The rats were unrelated, unfamiliar with each other and naive to the diets. The demonstrator could be reused, but not the observers. The pre-test habituation periods were 4 days for the observers and 3 weeks for the demonstrators.

\section{Apparatus and diets}

Demonstrators were kept separately in stainlesssteel cages $(28 \times 23 \times 20 \mathrm{~cm})$ and observers in suspended wire cages $(20 \times 24 \times 27 \mathrm{~cm})$. All rats were housed individually except during interaction periods when each observer and the appropriate group of demonstrators were transferred to stainless-steel cages measuring $45 \times 35 \times 25 \mathrm{~cm}$ for social interaction. The test diets used in learning trials were ground Purina Laboratory Rodent Chow mixed either with $1 \%$ Schilling ground cinnamon (Diet CIN), or with $2 \%$ Hershey's cocoa powder (Diet COC). Neither the cocoa nor the cinnamon contained sugar or other sweeteners. These two diets were preferred approximately equally on a preliminary test of first-taste without social interaction. The diets were served in plastic cups ( $5 \mathrm{~cm}$ diameter, $10 \mathrm{~cm}$ high).

\section{Procedures}

Figure 2 outlines the general procedure. The demonstrators were first deprived of food for $24 \mathrm{~h}$, and were then offered either Diet CIN or Diet COC for $1 \mathrm{~h}$. The observer, after 1 day of habituating to plain ground chow served in two plastic food cups, interacted with a group of four demonstrators simultaneously in a testing cage for $30 \mathrm{~min}$. There were five different demonstrating groups based on the ratios of the number of COC demonstrators to CIN demonstrators in each group $(0: 4,1: 3,2: 2,3: 1$ and 4:0). After social interaction, each observer was given a two-choice ( $30 \mathrm{~g}$ Diet CIN versus $30 \mathrm{~g}$ Diet COC) preference test for $24 \mathrm{~h}$. The preference for Diet COC was measured as the consumption of Diet COC divided by the total intake of Diet CIN and Diet COC. This preference was compared among five groups of observers by ANOVA test, and was also regressed against the ratios of demonstrator types of the five groups. We also used analysis of covariance to compare regression lines.

\section{Results}

Preference for Diet CIN differed between the five observer groups $\left(F_{4,35}=6.014, P<0.001\right)$. In other words, the observers were sensitive to the ratio of demonstrators. The greater the proportion of one type of demonstrator who ate one of those diets, the greater their observers preferred that diet. Although the demonstrator ratios were related linearly to the observers' preferences for percentage Diet $\operatorname{COC}\left(F_{1,38}=19 \cdot 39, R^{2}=0.34, P<0.001\right)$, a test for departure from a linear regression was significant $\left(F_{3,35}=50 \cdot 72, P<0 \cdot 001\right)$. Instead, a quadratic polynomial regression provided the best fit $\left(F_{2,37}=12.63, \quad R^{2}=0.41, \quad P<0.001 ; \quad\right.$ Fig. 3a $)$. 


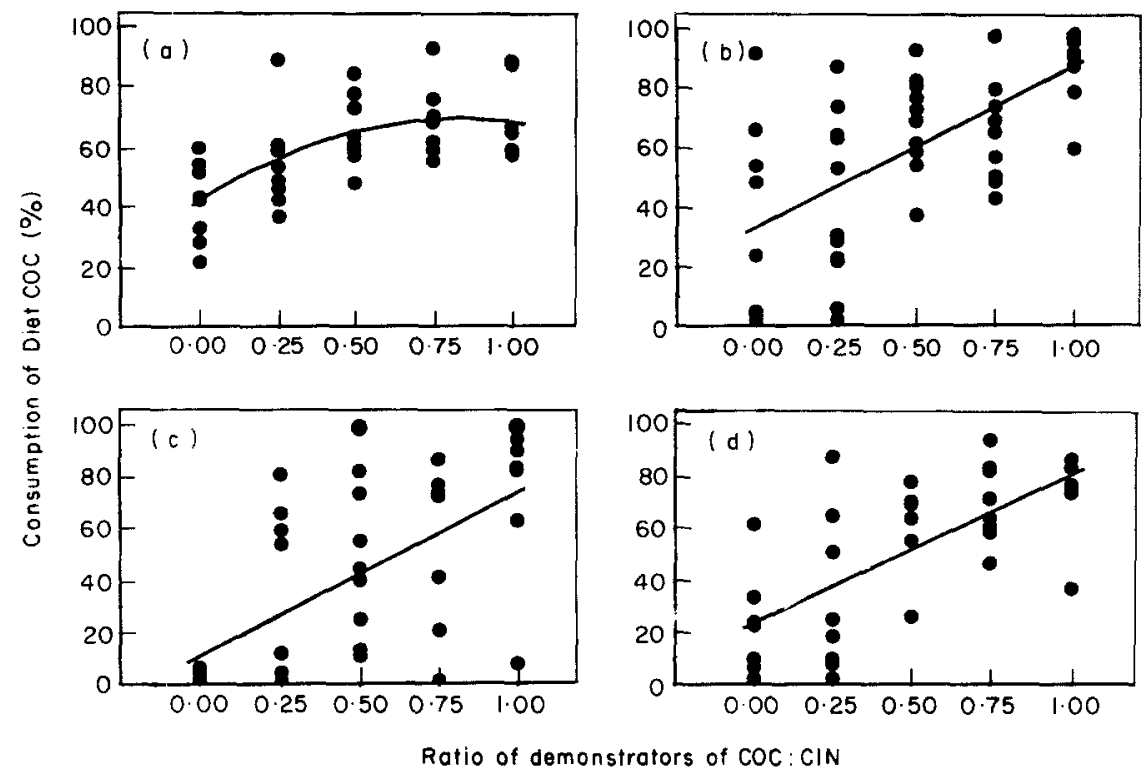

Figure 3. The observers' preference response to five different demonstrator ratios in (a) Sprague-Dawley rats, (b) -(d) Long Evans rats: (b) for female observers; (c) for male observers; (d) for pup observers.

Thus. a direct bias appears to have been involved in the social transmission of dietary information in Sprague-Dawley rats, because the observers showed a disproportionate preference for Diet COC when only a few (one or two) COC demonstrators were added to the demonstrating groups.

\section{EXPERIMENT 2: LONG-EVANS RATS}

The purpose of this experiment was to estimate the variability of the social transmission process as a function of rat sex, age and strain. Long-Evans rats were used and the results were compared with those from the previous experiment using SpragueDawley rats to test for a strain effect. The demonstrators were again adult females, whereas the observers were of three types: adult females; adult males at puberty; and weaned pups.

\section{Methods}

\section{Subjects}

Long-Evans rats, also obtained from Simonsen Laboratories, were bred in the Vertebrate Ecology Laboratory, University of California, Davis. Twenty second-generation females (110-150 days of age) were selected as demonstrators. Half the demonstrators had experience of cinnamon diet, the other half of cocoa diet. Forty-eight adult females (74-77 days of age) and 42 subadult males (45 48 days of age, near puberty) served as observers. The males' ages were limited because mature males tended to attempt actively to mate with the adult females in the interaction stage of learning trials. The youngest observers were 80 weanling pups ( $31-33$ days old with both sexes).

\section{Procedures}

The procedure for the adult female and subadult male observers was the same as in experiment 1 , whereas that for the young pups was similar, but (1) the pups were housed in pairs in each testing cage to avoid any possible isolating effect on the pups behaviour; and (2) ceramic bowls $(9 \mathrm{~cm}$ high. $4.5 \mathrm{~cm}$ diameter) were used instead of the plastic cups for food containers.

\section{Results}

The observers' dietary preferences for Diet COC differed between the five demonstrator ratio groups regardless of the sex or age of the observers. The $F$ values were $8.60(d f=4,43, P<0.0001)$ for female observers, $5.97(d f=4,37, P<0.0001)$ for males and $10.42(d f=4,35, P<0.0001)$ for pups. These differences were well explained by a linear regression for 
all three types of observers $\left(F_{1,46}=31.08\right.$ for females, $F_{1,40}=22.43$ for males and $F_{1,38}=37.39$ for pups, $P \mathbf{s}<0 \cdot 001$; Fig. 3b, c, d). Because of high variation in dietary preference among individuals, the $R^{2}$ values obtained were only $0 \cdot 41,0 \cdot 36$ and $0 \cdot 50$ for females, males and pups, respectively. Using Barlett's test (Montgomery 1984), the assumption of equal variances was found to be violated only in the case of male observers $(P<0.01)$, but not for pups $(P>0.05)$ or females $(P>0.01)$. By the BoxCox method (Montgomery 1984), the best transformation for the male preference response was a square root. Following that transformation, the relationship between the demonstrator ratio and the observer's preference response was still best described by a simple linear relationship.

\section{Strain, sex and age class comparisons}

The regression curve of Sprague-Dawley females was quadratic, while that of Long-Evans females was simple linear. This suggests that social transmission of different rat strains could involve different biases; unbiased in Long-Evans and direct bias in Sprague-Dawley rats. Using the analysis of covariance for pairwise comparison among three linear regressions of Long-Evans rats, we found no difference between three slopes $\left(F \mathrm{~s}<1, P_{\mathrm{S}}>0 \cdot 6\right)$. The regression intercept of males was lower than that of females $\left(F_{1,86}=8.85, P<0.01\right)$, while there was no difference for those of males versus pups, nor females versus pups $\left(F_{\mathrm{S}}<2 \cdot 7, P_{\mathrm{S}}>0 \cdot 1\right)$. In other words, although the social transmission mechanism of Long-Evans rats most probably involves no bias, the strength of social transmission did not show significant sex or age variation, except that the baseline preference for Diet COC was significantly lower for male rats.

\section{DISCUSSION}

The low explained variance $\left(R^{2}\right)$ in the regression analysis was due to a large amount of variation in the observers' preference response in each experimental group. This larger variation resulted from great individual variation, which could be diminished in future experiments by increasing the sample size. Two factors that may have influenced the variation in response are social familiarity among observer and demonstrator group members, and the individual learning effect. Although
Galef et al. (1984) showed that social familiarity between the demonstrator and the observer is not important for social learning to occur, their experimental situation dealt only with one demonstrator in each trial. However, when the number of demonstrators is increased, such as in our experimental situation, the social relationship between five rats (a temporarily formed mini-society) could be more complex. For example, one of us (L.-S.C.) frequently heard rats squeal during the interaction period. Therefore, tension could exist in a newly formed mini-society which might affect the capacity for social learning. Thus, social unfamiliarity could lead to high levels of variation in social transmission results. The second explanation is an individual learning effect. Because rats show a high tendency to sample new food, the individual learning dietary preference could be an obvious strong influence on dietary preference. In terms of the equations introduced, parameter $a$ is much smaller than 1 , and it leaves the term $1-a$ non-trivial. Thus, the $X$ value cannot perfectly express the final decision of response $Y$.

The relationship between the observer's response and the demonstrator ratio seemed to differ between the two strains: a quadratic linear function was obtained for Sprague-Dawley rats, whereas a simple linear function was obtained for LongEvans rats. Differences between these two strains have also been found in physical development (Robinson 1965; Clark \& Price 1981), behavioural performance (Robinson 1965; Cottle \& Price 1987) and emotion (Stone 1932; Broadhurst 1958). The sex and age classes of Long-Evans rats did not vary significantly in the type of bias or the strength of social transmission, except that the baseline of innate preference for certain Diet COC could be lower for males than females.

Galef \& Wigmore (1983) and Galef \& Stein (1985) showed that the transmitting mechanism for food preference was through the olfactory cue of the flavoured diet in the demonstrator's breath. Galef et al. (1988) determined that the major olfactory components of rat breath are carbon disulphide $\left(\mathrm{CS}_{2}\right)$ and carbonyl sulphide (COS). The presence of carbon disulphide enhanced the observer's later preference, similar to the effect of the presence of an anaesthetized demonstrator rat. Therefore, the social transmission mechanism for dietary information at an area distant from the food site could be merely a simple mechanism resulting from the combination of breath odour 
component(s) and dietary odour modified by the innate preference of rats expressed through individual learning and direct bias. More complicated mechanisms, such as frequency-dependent bias and indirect bias which often occur in human social transmission, are yet to be demonstrated in the social transmission of dietary information in rats. However, broadening the view of Galef \& Kaner's (1980) 'sensory-affective bias' (by which I believe is meant innate taste bias), which is genetically determined and biased rats could show a biased attitude towards a particular combination of the demonstrator's breath and dietary odour, and could thus show direct bias in the social transmission process. Frequency-dependent and indirect bias, however, probably need more complex mechanisms in rat cognition for dietary decision-making.

\section{ACKNOWLEDGMENTS}

We are extremely grateful to $\mathrm{Dr}$ W. E. Howard and R. E. Marsh for their generous admission to access the equipment, space and supplies in their laboratory. We also thank Dr R. Boyd for his comments on earlier versions of the manuscript and J. Fahrni, A. Koahler, Dr K. S. Smallwood and Dr B. Stein for reading the manuscript.

\section{REFERENCES}

Boyd, R. \& Richerson, P. J. 1985. Culture and the Evolutionary Process. Chicago, Illinois: University of Chicago Press.

Broadhurst, P. L. 1958. Determinants of emotionality in the rat: III. Strain differences. J. comp. physiol. Psychol., 51, 55-59.

Chou, L.-s. 1989. Social transmission of food selection by rats, Rattus spp. Ph.D. thesis, University of California, Davis.

Clark, B. R. \& Price, E. O. 1981. Sexual maturation and fecundity of wild and domestic Norway rats (Rattus norvegicus). J. Reprod. Fert., 63, 215-220.

Cottle, C. A. \& Price, E. O. 1987. Effect of the nonagouti pelage-color allele on the behavior of captive wild Norway rats (Rattus norvegicus). J. comp. Psychol., 101, 390-394.

Galef, B. G., Jr. 1977. Mechanisms for the social transmission of food preferences from adult to weaning rats. In: Learning Mechanisms in Food Selection (Ed. by
L. M. Barker, M. Best \& M. Domjan), pp. 123-150. Wavo: Baylor University Press.

Galef, B. G., Jr. 1983. Utilization by Norway rats (Rattus norvegicus) of multiple messages concerning distant foods. J. comp. Psychol., 97, 364-371.

Galef, B. G., Jr. 1985. Direct and indirect behavioral pathways to the social transmission of food avoidance. Ann. N.Y. Acad. Sci., 443, 203-215.

Galef, B. G., Jr. 1988. Communication of information concerning distant diets in a social, central-place foraging species: Rattus norvegicus. In: Social Learning: Psychological and Biological Perspectives (Ed. by T. R. Zentall \& B. G. Galef, Jr), pp. 119-140. Hillsdale. New Jersey: Lawrence Erlbaum.

Galef, B. G., Jr. 1990. Responses of oberserver rats (Rattus norvegicus) to complex, diet-related signals emitted by demonstrator rats. $J$. comp. Psychol., 104, 11-19.

Galef, B. G., Jr \& Kaner, H. C. 1980. Establishment and maintenance of preference for natural and artificial olfactory stimuli in juvenile rats. $J$. comp. physiol. Psychol., 94, 588-595.

Galef, B. G., Jr., Kennett. D. J. \& Wigmore, S. W. 1984. Transfer of information concerning distant foods in rats: a robust phenomenon. Anim. Learn. Behav., 12. 292-296.

Galef, B. G., Jr, Mason, J. R., Preti, G. \& Bean, N. J. 1988. Carbon disulfide: a semiochemical mediating sociallyinduced diet choice in rats. Physiol. \& Behav., 42. $119-124$.

Galef, B. G., Jr \& Stein, M. 1985. Demonstrator influence on observer diet preference: analyses of critical social interactions and olfactory signals. Anim. Learn. Behav.. 13, 31-38.

Galef, B. G., Jr \& Wigmore, S. W. 1983. Transfer of information concerning distant foods: a laboratory investigation of the 'information-centre' hypothesis. Anim. Behav., 31, 748-758.

Kawai, M. 1965. Newly acquired pre-cultural behavior of the natural troop of Japanese monkeys on Koshima Inlet. Primates, 6, 1-30.

Lefebvre, L. 1986. Cultural diffusion of a novel foodfinding behaviour in urban pigeons: an experimental field test. Ethology, 71, 295-304.

Montgomery, D. C. 1984. Design and Analysis of Experiments. 2nd edn. New York: John Wiley.

Posadas-Andrews, A. \& Roper, T. J. 1983. Social transmission of food-preferences in adult rats. Anim. Behav., 31, 265-271.

Robinson, R. 1965. Genetics of the Norway Rat. London: Pergamon Press.

Stone, C. P. 1932. Wildness and savageness in rats of different strains. In: Studies in the Dynamics of Behavior (Ed. by K. S. Lashley), pp. 3--55. Chicago, Illinois: University of Chicago Press.

Zentall, T. R. \& Galef, Jr. B. G. 1988. Social Learning: Psychological and Biological Perspectives. Hillsdale, New Jersey: Lawrence Erlbaum. 